\title{
Morphology and morphogenesis of infectious salmon anaemia virus replicating in the endothelium of Atlantic salmon Salmo salar
}

\author{
Christian W. R. Koren ${ }^{1}$, Are Nylund ${ }^{2}$ \\ ${ }^{1}$ Department of Arctic Veterinary Medicine, Norwegian College of Veterinary Medicine, N-9005 Tromsø, Norway \\ ${ }^{2}$ Department of Fisheries and Marine Biology, HiB, University of Bergen, N-5020 Bergen, Norway
}

\begin{abstract}
Thin section electron microscopy of tissues from farmed Atlantic salmon Salmo salar L. with clinical infectious salmon anaemia revealed virus budding from endothelial cells. The typical enveloped virus particle showed a regularly arranged filamentous nucleocapsid and a matrix proteinlike structure. Virus was budding from the plasma membrane, mainly at the luminal side, and also from certain intracellular membranes. Morphology and morphogenesis resembled orthomyxoviruses. In addition to the typical spherical particles (diameter $100 \mathrm{~nm}$ ), defective particles, filamentous particles, tubular membrane projections and cytoplasmic nucleocapsid inclusions were observed. Lysis of virus producing cells was infrequently found and was associated with excessive formation of viral structures.
\end{abstract}

KEY WORDS: Infectious salmon anaemia virus (ISAV) $\cdot$ Virus morphology $\cdot$ Endothelial cell $\cdot$ Atlantic salmon

\section{INTRODUCTION}

Infectious salmon anaemia is a viral disease of farmed Atlantic salmon Salmo salar L. The disease has only been observed in fish from Norway (Thorud \& Djupvik 1988, Thorud 1991, Nylund \& Jacobsen 1995 , Nylund et al. 1995a, c). Virus particles, mainly budding from endothelial cells and occasionally observed in vacuoles of leucocytes, have been described in the tissues of experimentally infected Atlantic salmon (Hovland et al. 1994, Nylund et al. 1995b). Particles of similar morphology have also been reported from studies of a cell culture supporting the growth of the infectious salmon anaemia virus (ISAV) (Dannevig et al. 1995) and ISAV-infected head kidney macrophage cultures (Sommer \& Mennen 1996).

The confinement of ISAV to Norway may be due to the lack of extensive examination and the difficulty in detecting this agent, and may not reflect the true distribution of this pathogen. A detailed description of ISAV morphology may facilitate recognition of similar viruses encountered elsewhere. Also, information about the morphology and morphogenesis of ISAV may contribute to an understanding of the pathogenesis and suggest a taxonomic relationship. In this study, transmission electron microscopy (TEM) of thin sections from tissues was used to describe the ISAV and the replication of virus in target cells.

\section{MATERIALS AND METHODS}

Moribund farmed Atlantic salmon from naturally occurring outbreaks of infectious salmon anaemia were sampled for TEM. Each group consisted of 5 salmon weighing 2 to $5 \mathrm{~kg}$. The first group was sampled in 1986 (farm A) and the second group in 1994 (farm B). Tissues from farm A were placed in 3\% glutaraldehyde in cacodylate buffer and stored in this fixative at $4^{\circ} \mathrm{C}$ for 8 yr. Specimens from farm B were fixed in $4 \%$ formaldehyde and 1\% glutaraldehyde in phosphate buffer with $2.6 \%$ sucrose (modified after McDowell \& Trump 1976). The tissues (stomach, intestine, liver, heart, gills, kidney and spleen) were post-fixed in $1 \%$ osmium tetroxide for $90 \mathrm{~min}$, block-stained in $2 \%$ uranyl acetate, dehydrated in ethanol and embedded 
in epon-araldite. The ultrathin sections (50 to $80 \mathrm{~nm}$ ) were stained with uranyl acetate and lead citrate (Reynolds 1963).

The following description of the ISAV is based on examination of 109 thin sections from 2 farms ( 65 from farm $\mathrm{A}$ and 44 from farm $\mathrm{B}$ ) where virus particles were observed associated with endothelial cells. Farm A was included in this study because it was involved in the first known epidemic of infectious salmon anaemia. The same material was also used in a pathological study of this disease (Koren unpubl.).

Electron micrographs used for measuring virion diameter and substructures were carefully selected to ensure the highest resolution. Moreover, these measurements were taken on 20 particles with a distinct membrane only, since the membrane will only be distinct in viruses that have been sectioned through the centre or close to the centre.

\section{RESULTS}

\section{Virion}

The ISAV particles from the 2 farms were morphologically similar. However, virions from farm A (prolonged storage in fixative) generally stained more densely and were slightly smaller (Table 1). The most prevalent ISAV particles were spherical and relatively uniform with a diameter of approximately $100 \mathrm{~nm}$. The envelope was a distinct unit membrane where the inner electron-dense lamina appeared to be continuous with an electron-dense inner lining (Fig. 1b). This area tended to separate into 2 zones at high magnifications (not shown). The inner lining was also clearly visible in certain aberrant particles (Fig. 2c), but was absent in others (Fig. 1b). A layer of moderately elec-

Table 1. ISAV measurements

\begin{tabular}{|lcccc|}
\hline ISAV measurement (nm) & Mean & Min & Max & $\mathrm{n}$ \\
\hline Particle diameter (farm A ${ }^{\mathrm{a}}$ ) & 94 & 86 & 106 & 10 \\
Particle diameter (farm B & 106 & 99 & 115 & 10 \\
Particle diameter (farm A and B) & 100 & 86 & 115 & 20 \\
Surface (spike) layer & 7 & 5.9 & 8.3 & 13 \\
Envelope outer lamina (dense) & 2.6 & 1.8 & 3.5 & 20 \\
Envelope middle lamina (lucent) & 2.1 & 0.8 & 5.5 & 20 \\
Envelope inner lamina and lining & 6.2 & 3.9 & 7.8 & 20 \\
Dot diameter & 9.8 & 6 & 13 & 114 \\
Dot interdistance (outer circle) & 16.5 & 12 & 26 & 49 \\
Dot interdistance (inner circle) & 15.5 & 12 & 23 & 21 \\
& & & & \\
a Different fixatives and storage times were used for speci- \\
mens from farm A and B
\end{tabular}

tron-dense material, about $7 \mathrm{~nm}$ thick, was frequently found on the surface of the virions (Figs. 1 b \& 2c). This was sometimes continuous with a ragged halo $(50 \mathrm{~nm})$ observed on particles in the lumen of vessels (Fig. 1). The interior of the virus particles contained electrondense structures that appeared to be regularly arranged. In most sections these structures were visible as several dots (10 $\mathrm{nm}$ in diameter) and in others more like curved strands. In some sections the dots were arranged in 2 concentric circles. The outer circle, close to the membrane inner lining, consisted of 12 to 14 dots and the inner circle of about 6 dots (Fig. 1). The distance between the centres of adjacent dots in these circles was about 15 to $17 \mathrm{~nm}$ (Table 1). Budding particles tended to be slightly oblong and the core structures formed strands rather than distinct dots (Fig. 2a, b).

\section{Aberrant particles and membrane structures}

Several types of aberrant or defective virus particles were frequently observed. These were most abundant when large complexes of virus particles and membrane structures were encountered. Rod-shaped filamentous forms (300 to $600 \mathrm{~nm}$ long) were rare, but several of these particles were occasionally associated with the same cell (Fig. 3a, b, e). The diameters of these filamentous forms ( 60 to $70 \mathrm{~nm}$ ) were only about $70 \%$ of the regular particles and some rod-shaped particles had curved ends (Fig. 3a, b). Electron-dense spots (15 to $20 \mathrm{~nm}$ ) were often present in the core at both ends of the particle. Wave-shaped filamentous forms with an apparently empty interior were also observed (Fig. 3c, d). Their 3-dimensional structure seemed to be helical.

A particle type with diameter about $170 \mathrm{~nm}$ (Fig. 2c) had a core consisting of a reticulum of filamentous structures. The envelope consisted of 2 halves (hemispheres) with a dense inner lining connected by a narrow region without lining. Another particle type (about $100 \mathrm{~nm}$ ) with a condensed polygonal electrondense core and no membrane inner lining was frequently observed (Fig. 1b). In a few instances it seemed that the core was made up of a cluster of tightly packed $10 \mathrm{~nm}$ dots.

Tubular membrane structures, often accompanying budding of typical virions (Figs. 1, 4a, c, 5 \& 6), were sometimes the only structures observed (Fig. 6a). Typically they displayed a ragged surface, no membrane inner lining and were apparently empty inside. Occasionally such structures were continuous with straight tubules having a dense lining (Fig. 3e). The diameters of the pleomorph tubular membrane structures were mainly in the range of 50 to $200 \mathrm{~nm}$. 


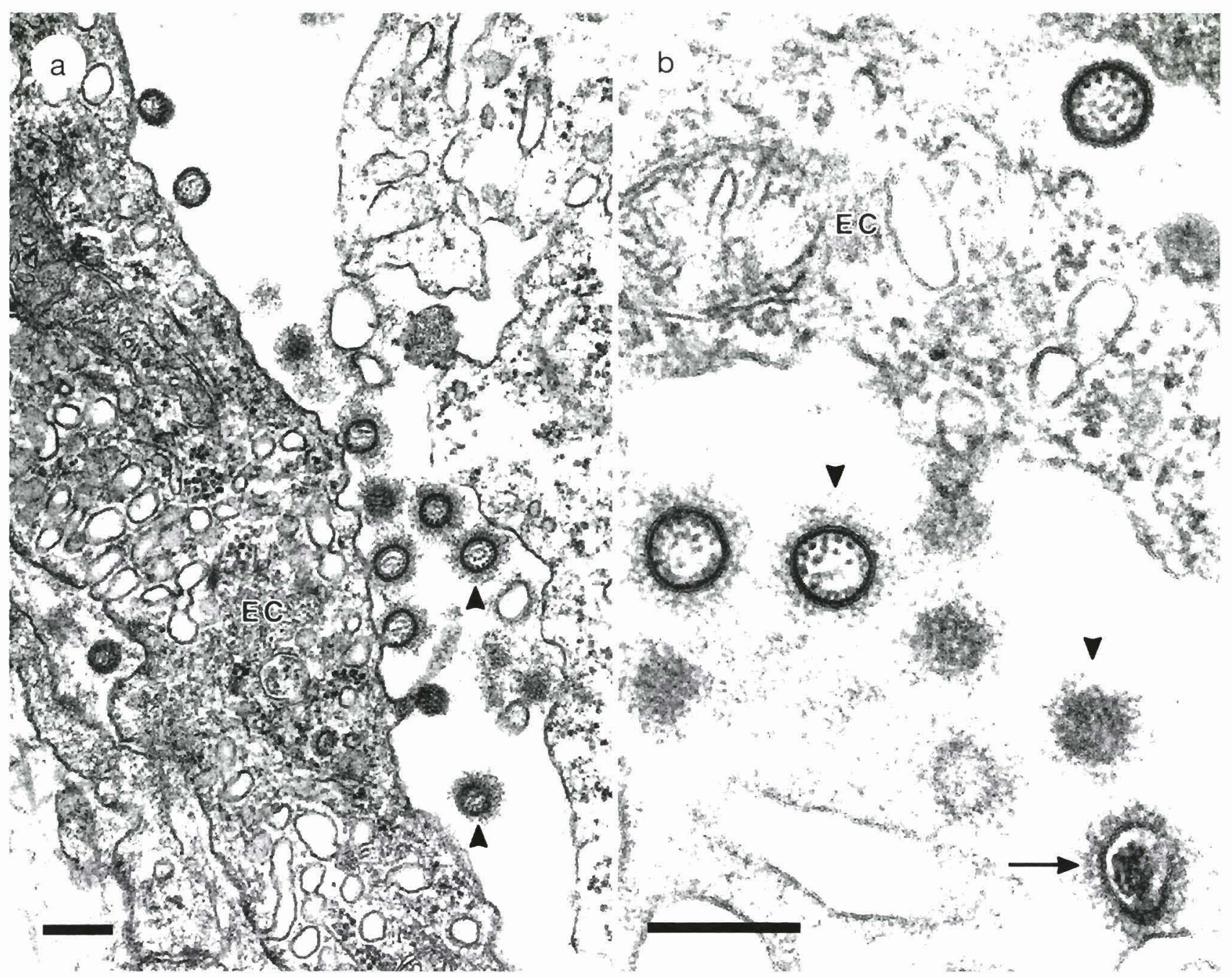

Fig. 1. ISAV structures in Salmo salar. (a, b) A halo of amorphous substance (arrowheads) surrounds the virions and membrane tubules at the luminal side of endothelial cells (EC), but not the virions at the abluminal side. (b) Note typical ISAV trilaminar envelope with thicker inner lamina and regularly arranged dots in the core, except the particle with a condensed core (arrow).

$(\mathrm{a}, \mathrm{b})$ Anterior intestine. Scale bars $=200 \mathrm{~nm}$

\section{Intracellular structures}

Cytoplasmic inclusions, up to $2.5 \mu \mathrm{m}$ wide (Fig. 7), were present in endothelial cells, which also exhibited large amounts of other viral structures. The inclusions consisted of longitudinal and transverse-sectioned, moderately electron-dense strands about $10 \mathrm{~nm}$ wide and up to $150 \mathrm{~nm}$ long. The spacing between strands appeared relatively uniform with a periodicity of 20 to $25 \mathrm{~nm}$ for parallel strands. If vesicles were located inside these inclusions, the surrounding strands tended to be radially oriented (Fig. $2 b$ ).

Densely stained structures surrounded by ribosomes were sometimes observed in connection with the endoplasmic reticulum of virus-producing cells (Fig. $7 \mathrm{~b}$ ). Densely stained strands (diameter 60 to $70 \mathrm{~nm}$ ) with lucent interiors frequently occurred in the nuclei of endothelial cells in regions of virion formation (Fig. $4 \mathrm{~d}$, e). These tubular-like structures were associated with heterochromatin.

\section{Morphogenesis and formation of complexes}

ISAV was found budding from the plasma membrane and apparently also from internal membranes of endothelial cells. Assembly of the virions appeared to take place at the site of budding. Occasionally we observed areas of the plasma membrane with a densely stained inner layer (Fig. 6a). These areas probably represented early stages of the budding process that did not mature into virions because of some defect. Later stages of the 


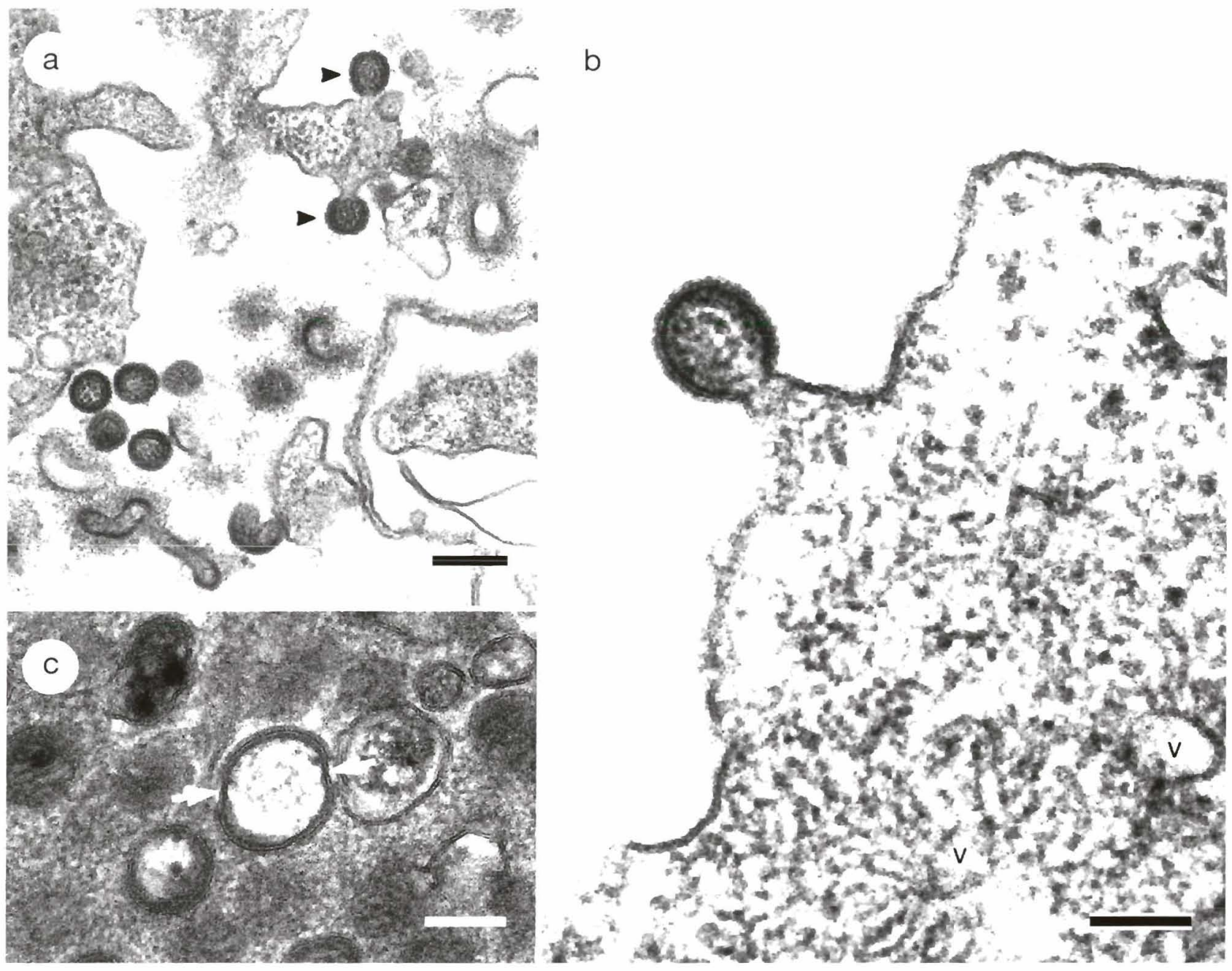

Fig. 2. ISAV structures in Salmo salar. (a) Virions in the state of budding (árrowheads) tend to have a rectangular shape with rounded corners rather than the circular shape of free virions. Stomach. (b) A slightly oblong particle budding. Cytoplasmic inclusion consists of strands and dots, some parallel strands are oriented radially around small vesicles (V). Anterior intestine. (c) A large particle $(170 \mathrm{~nm}$ diameter) consisting of 2 halves with surface layer and inner lining. Note the reticular arrangement of filaments in the core and that the inner lining is lacking at the joining regions (arrows). Heart. Scale bars: (a) $=200 \mathrm{~nm}$, $(\mathrm{b}, \mathrm{c})=100 \mathrm{~nm}$

budding process were frequently seen as particles connected to the plasma membrane through a short stalk only (Fig. 2a, b). The number of virus particles and amount of virus-associated structures formed per endothelial cell (in the plane of section) varied from a few particles only to large complexes of membrane structures and particles, often 'bush'-shaped (Fig. $4 \mathrm{a}-\mathrm{c}$ ).

When small numbers of virions ( 1 to 4 ) were encountered, they were usually located singly at the plasma membrane surface. Most frequently, groups of 5 to 20 virions were encountered, usually concentrated in a minor area at the luminal side with only a few single particles present at the abluminal side (Figs. 1a \& 4 b). Tubular membrane protrusions and some ridge-like cytoplasmic processes were generally intermingled with virions. Virions budding from the ridge-like extensions were observed. In a few cells spherical virions and fine granular material were found inside multivesicular bodies (Fig. 7a). Except for the densely stained structures in the nucleus (Fig. 4d, e), alterations in cellular morphology were generally not observed. Occasionally, lysed cells continuous with viral structures were observed in the lumen of vessels and the heart (Fig. 6b).

High numbers of virions ( $>20$ ) were infrequent and generally found in large complexes composed of tubular or reticular membrane structures, virus particles (many aberrant) and a fine granular moderately electron-dense substance. Such structures occasionally extended into the lumen of vessels (Fig. 4c) or vir- 


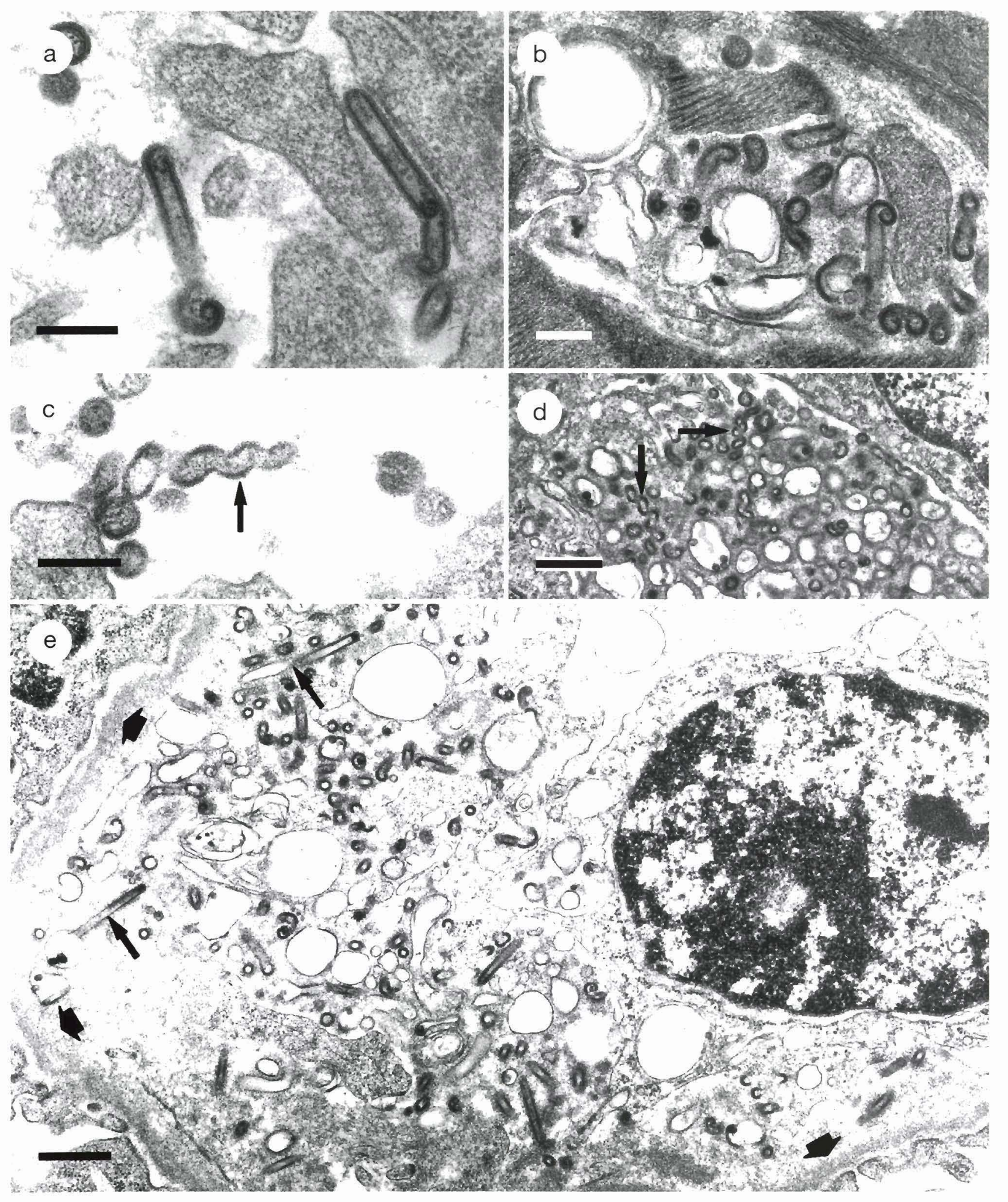

Fig. 3. Filamentous ISAV structures in Salmo salar. (a, b) Straight filamentous particles. The envelope is sometimes terminated in a curl-like structure. (a) Anterior intestine. (b) Heart. (c, d) Helical filamentous particles (arrows). (c) Anterior intestine. (d) Heart. (e) Vacuolized endothelial cell with virus associated tubular structures adjacent to the vacuoles and to the basal lamina (short arrows). These appears to be transition between structures with and without dense inner lining (arrows). Note dilatation of nuclear envelope. Glomeruli. Scale bars: $(\mathrm{a}-\mathrm{c})=200 \mathrm{~nm} ;(\mathrm{d}, \mathrm{e})=500 \mathrm{~nm}$ 


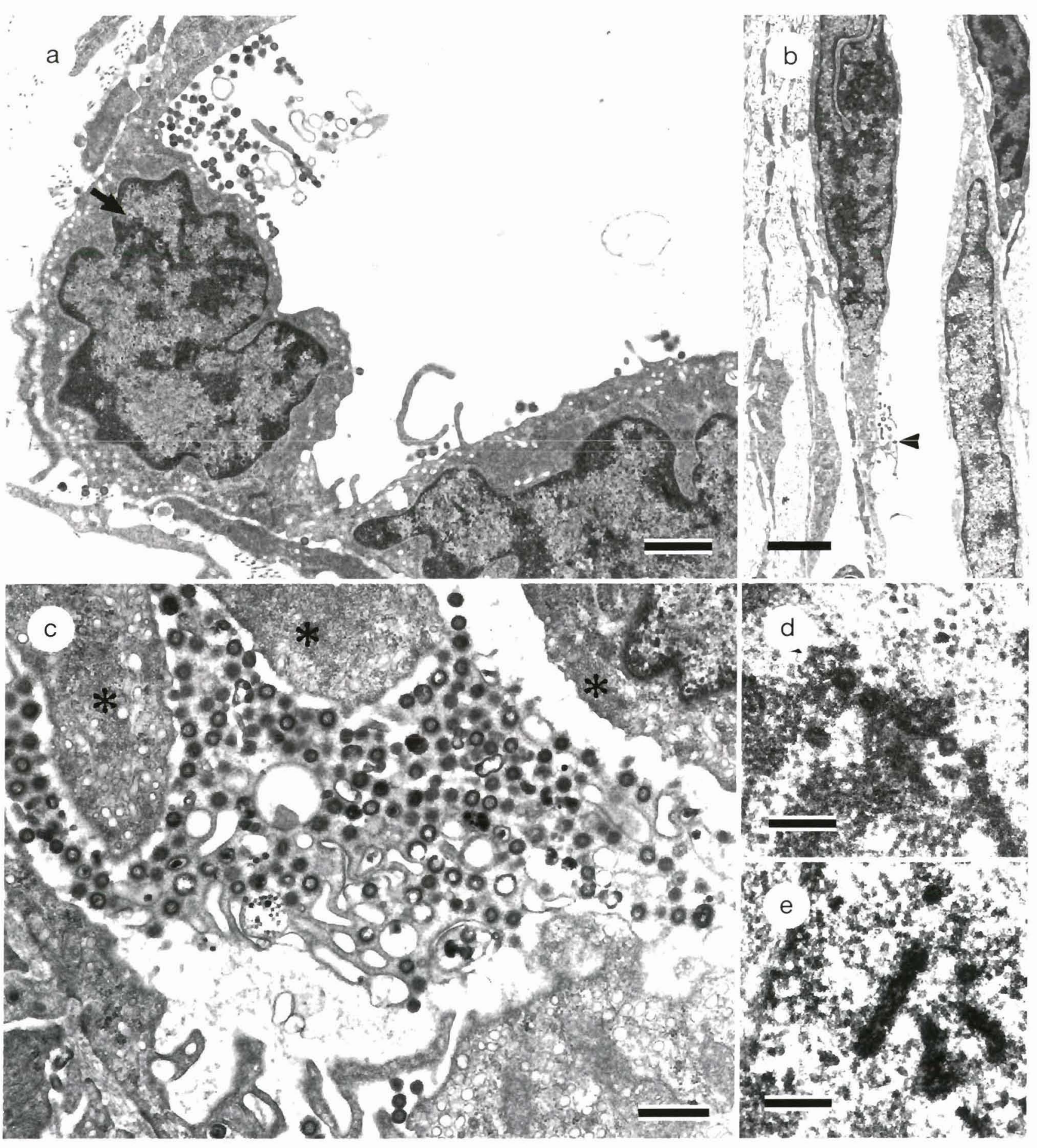

Fig. 4. Formation of ISAV-associated structures and virions in Salmo salar. (a) Moderate (upper) and low (lower right) numbers of ISAV located at the luminal side of endothelial cells. A few particles also at the abluminal side. The arrow points to region also shown in (d). Anterior intestine. (b) Virus is budding into the lumen from a small area of the plasma membrane (arrowhead). Anterior intestine. (c) A large complex of virus particles in a capillary lumen (tubular membrane structures, virions, aberrant particles and a fine granular substance filling the space between these structures). Cytoplasmic inclusions consisting of strands (*) are present. Stomach. (d) Region of nucleus in (a) with 4 dense ring-like structures in-line. (e) Region of endothelial cell nucleus with densely staining tubular-like structures of the same diameter as rings in (d). Heart. Scale bars: $(a)=1 \mu \mathrm{m}$; (b) $=2 \mu \mathrm{m}$;

(c) $=500 \mathrm{~nm} ;(\mathrm{d}, \mathrm{e})=200 \mathrm{~nm}$ 

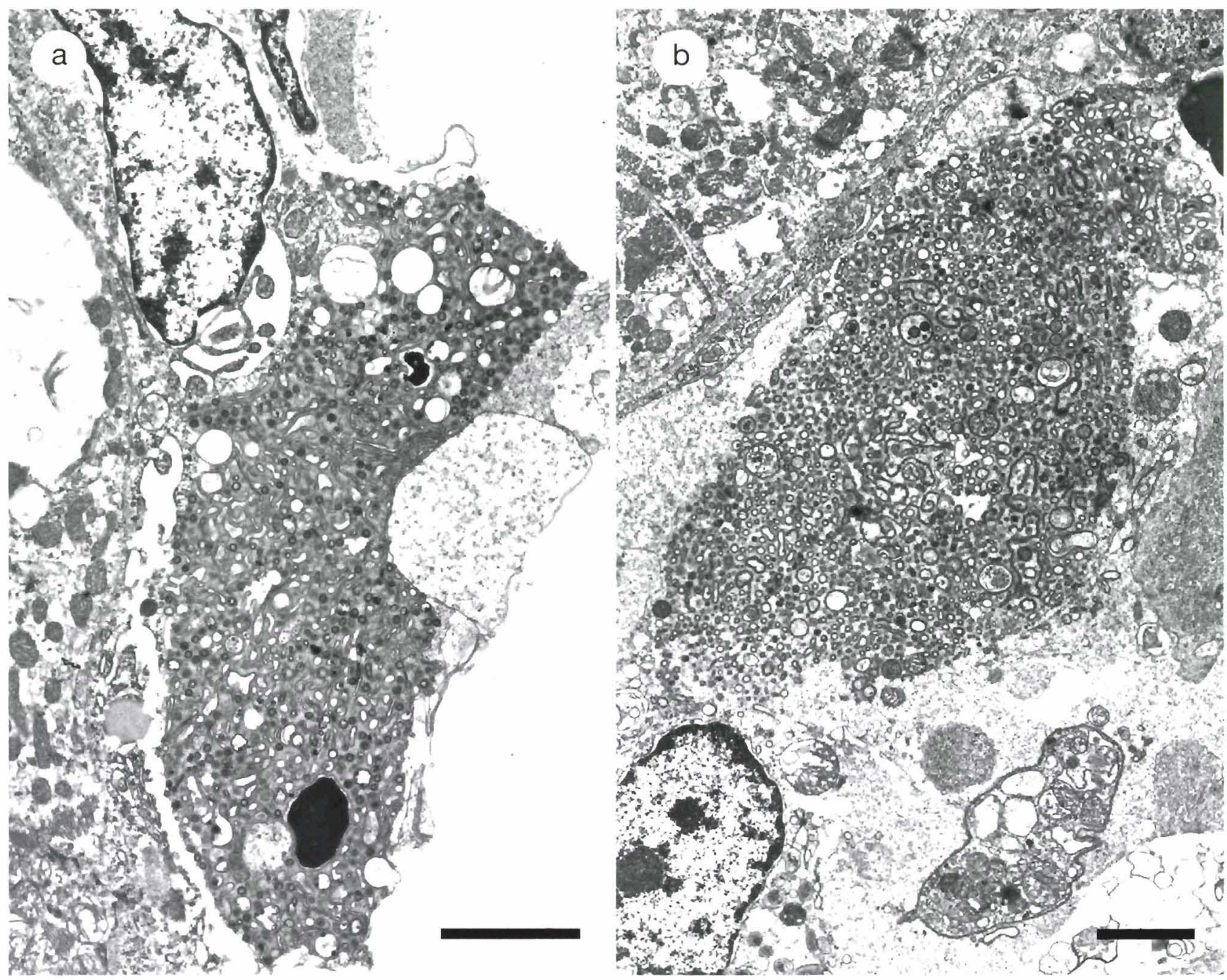

Fig. 5. (a) ISAV structures in Salmo salar. A large complex of densely packed virions and virus associated structures. The nuclear envelope is dilated and the cell is disintegrated. Heart. (b) A large $(16 \mu \mathrm{m})$ complex composed of virus-associated structures, mainly membrane tubules, but no typical virions. The cell appears to be lysed and debris are present in capillary lumen. Heart. Scale bars: $(\mathrm{a})=1 \mu \mathrm{m} ;(\mathrm{b})=2 \mu \mathrm{m}$

tually replaced the cytoplasm of some endothelial cells (Figs. 3e \& 5a), especially pillar cells (endothelial cells of gill lamellae) and glomerular endothelium. Dilatation of the nuclear envelope, cytoplasmic vacuolisation and inclusions were regularly present in these cells. Extremely large complexes of virus-associated structures (up to $16 \mu \mathrm{m}$ ), with or without typical virions (Fig. 5), were encountered in a few instances only and associated with disintegrated cells. The identity of these cells could not be determined.

\section{DISCUSSION}

Hovland et al. (1994) found the ISAV to be spherical particles with a diameter of approximately $100 \mathrm{~nm}$, whereas Dannevig et al. (1995) stated that particle diameters were 100 to $120 \mathrm{~nm}$ in thin sections and varied from 130 to $140 \mathrm{~nm}$ in negatively stained preparations. Dannevig et al. (1995) also described negatively stained particles with diameters as small as $45 \mathrm{~nm}$ and pleomorph filamentous particles up to $700 \mathrm{~nm}$ long. A minor difference between negative staining and thin sections is to be expected, because the negative staining technique generally causes some collapse of enveloped virus particles, resulting in an increased particle diameter. In the present study we have described a number of forms of virus particles and virus-associated membrane structures that explain why ISAV in some respects may give the impression of having a high degree of pleomorphism, although the regular particles of $100 \mathrm{~nm}$ are relatively uniform. 


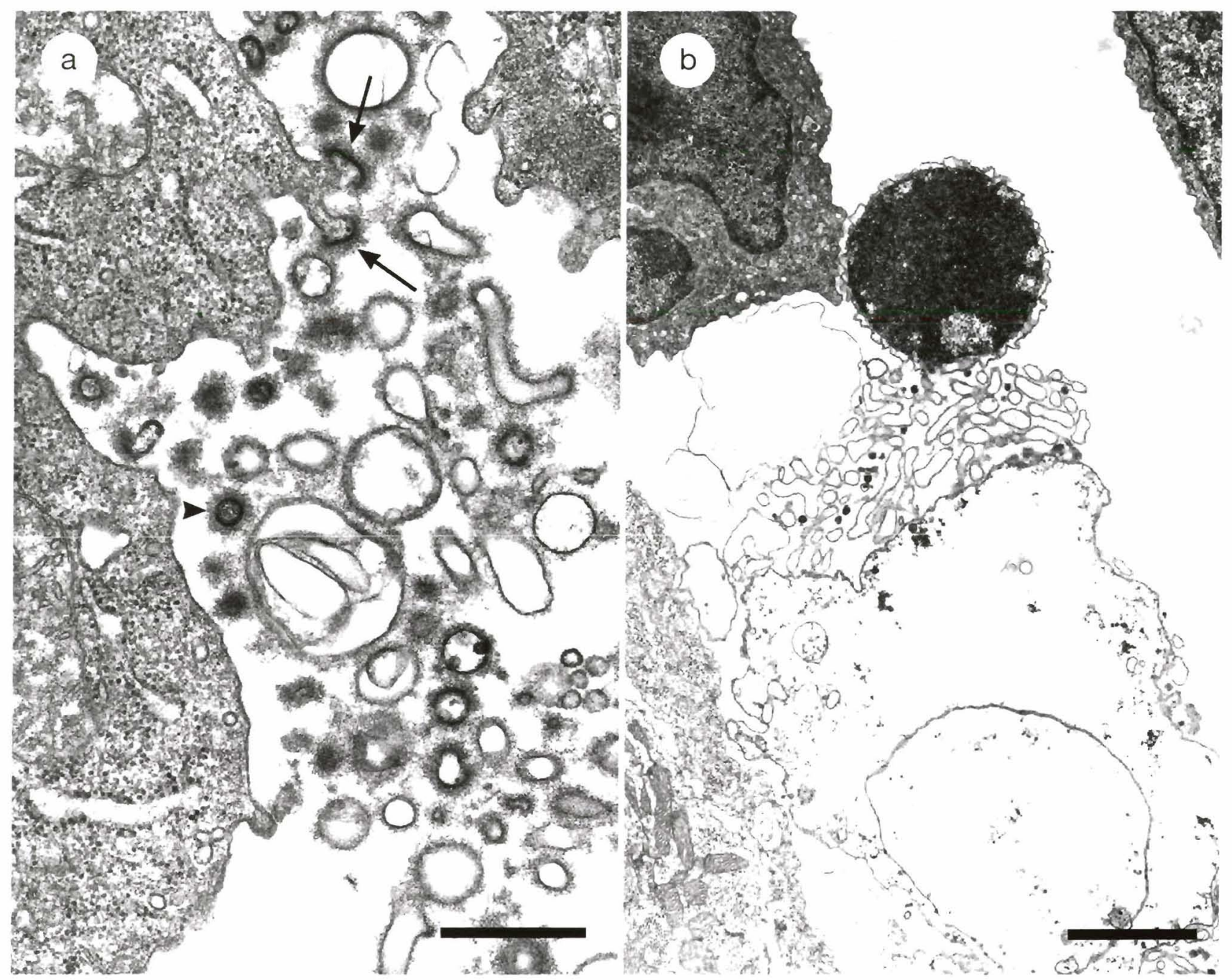

Fig. 6. ISAV structures in Salmo salar. (a) Normally sized complex of tubular membrane structures and a single virion (arrowhead). Note modified regions of plasma membrane protrusions (arrows) resembling budding. Anterior intestine. (b) A lysed cell in the lumen of the ventricle. Tubular membrane structures and a few virions are located between the nucleus and wide membranes holding some remnants of cytoplasm. Heart. Scale bars: $(\mathrm{a})=500 \mathrm{~nm}$; $(\mathrm{b})=2 \mu \mathrm{m}$

This typical and most frequently encountered particle $(100 \mathrm{~nm})$ is likely to be the functional one.

The structure of the nucleocapsid-like strands in the cytoplasmic inclusions corresponded well to the structure of strands in the core of the virions and these strands resemble those previously described (Sommer \& Mennen 1996). The lack of particles observed in the early stage of budding and assembly suggests that these steps occur very rapidly. The slightly elongated shape of the particles in the frequently observed late stage of budding may indicate that the nucleocapsid arrangement has a single axis of symmetry. Hence, the fraction of particles having a typical concentric arrangement of dots may represent transverse sections perpendicular to the axis. The observed close contact between the envelope inner lining and the dots repre- senting the nucleocapsid may indicate the binding of the nucleocapsid to the lining. This is to be expected if the lining represents a matrix protein. If the inner lining is not present when particles are formed, the nucleocapsid arrangement will be altered. This could possibly explain particles with condensed cores (Fig. 1b). Furthermore, large particles, apparently consisting of 2 halves that both had an inner lining, displayed structures in the core that may represent a stretched nucleocapsid arrangement (i.e. a defective double particle). The thickness of the supposed matrix protein layer, calculated to be about $3.5 \mathrm{~nm}$ (slightly less than the total inner lamina and lining, $6.2 \mathrm{~nm}$, minus inner lamina thickness substituted by outer lamina measurement, $2.6 \mathrm{~nm}$, Table 1), corresponds to influenza virus (Nermut 1972). 


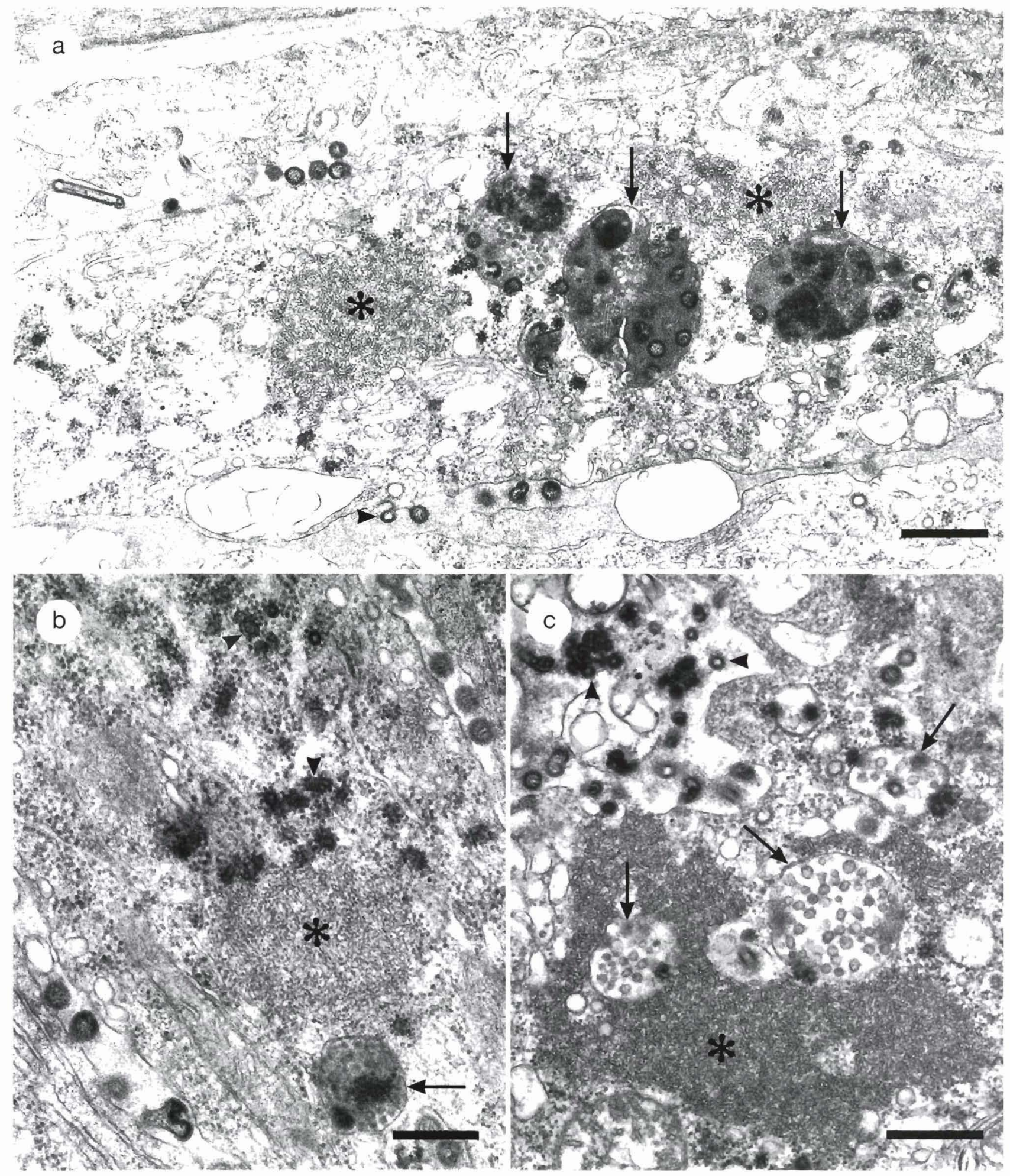

Fig. 7. ISAV structures in Salmo salar. Multivesicular bodies (arrows) and cytoplasmic inclusions consisting of strands (* ) occur in endothelial cells. (a) The multivesicular bodies appear partly filled with virions and a moderately dense amorph or fine granular substance. Virus is also budding from the plasma membrane (arrowhead). Anterior intestine. (b) Note several dense spots or ringlike structures surrounded by ribosomes (arrowheads). Anterior intestine. (c) Virus associated structures (arrowheads) Glomeruli. Scale bars: (a) $=500 \mathrm{~nm}$; (b) $=250 \mathrm{~nm} ;(\mathrm{c})=500 \mathrm{~nm}$ 
A marked feature of intense ISAV replication is the excessive proliferation of tubular membrane structures. If spikes are present, these structures may be identified as viral particles in negatively stained preparations. This may correspond to some of the large highly pleomorph particles observed by Dannevig et al. (1995) from unpurified medium of infected cell cultures. In the present study complexes of these membrane structures were found both as extensions from the plasma membrane and as membrane-bound intracellular complexes.

A few observations indicated that intracellular complexes may arise by budding into multivesicular bodies. These bodies may be identical to the multivesicular bodies normally found in endothelial cells and many other cell types (Ghadially 1988). Vesicles derived from the plasma membrane are likely to fuse with this type of endo-lysosomal structure. Alternatively, the structure may be virus-induced. Invaginations of the plasma membrane and vacuolisation are likely to be the mechanism of formation of some intracellular complexes, especially those observed in some structurally important endothelial cells (gills and glomeruli). Budding into Golgi vesicles, typical of bunyaviruses (Murphy et al. 1973), was not observed.

All virus modified membrane structures, with or without inner lining, appeared to curve, suggesting this was an intrinsic spatial property. This is exemplified by the formation of membrane tubules (50 to $200 \mathrm{~nm}$ ), the bulging envelope of budding virions, the fixed diameter of filamentous particles as well as their helical structure or curl-like termination.

The densely stained tubular structures occurring in nuclei (heterochromatin associated), cytoplasm (ribosome associated) and in some vacuoles (Fig. 7c) predominantly exhibited the same morphology. Although a viral nature cannot currently be proved for any of these structures, they are presumably virus-induced and their tubular structure may indicate a matrix protein. Influenza virus matrix protein occurs as dense structures in nucleus and cytoplasm (Patterson et al. 1988); however, non-structural proteins are reported from these sites also (Compans \& Dimmock 1969, Compans \& Choppin 1973, Oxford \& Schild 1990).

The halo surrounding virions as well as virusmodified membrane tubules in the vessel lumen, and the fine granular substance observed filling the space in complexes, seem to be identical. The substance appears to have attachment properties and may represent a surplus of surface protein or nucleoprotein. It may also consist of a product normally formed by endothelial cells, e.g. the basal lamina, from which it could not be readily distinguished morphologically. When this substance is not attached to a particle sur- face or trapped in complexes, it may be released into the circulation.

Previous studies have suggested a classification of ISAV based on morphology (Nylund et al. 1995b, Sommer \& Mennen 1996). Morphology of virus particles and mode of budding can be highly indicative of taxonomic relation if these characters correspond well to a type virus. ISAV has the structure of an enveloped RNA virus and closely resembles orthomyxoviruses in size and most structural aspects (Morgan \& Rose 1968, Bächi et al. 1969, Compans \& Dimmock 1969, Nermut 1972, Schulze 1972, Compans \& Choppin 1973, Oxford \& Schild 1990). An important exception is the nucleocapsid arrangement. The conspicuous dot pattern revealed in the electron micrographs does not agree with previous studies of influenzd virus. This suggests that the ISAV nucleocapsid arrangement possibly differs from that of influenza virus. The use of penetrating negative stains may help to clarify this, although the nucelocapsid arrangement of influenza virus is not completely understood either (Murphy \& Webster 1990).

The present study confirms previous descriptions of ISAV morphology (Hovland et al. 1994, Dannevig et al. 1995, Nylund et al. 1995b) and extends the morphological characterisation to a set of viral structures. This will allow identification of ISAV replication in ultrastructural studies when no typical virions but other viral structures are encountered. The results of this study suggest that the conspicuous morphology of the cross-sectioned envelope, described in detail for the first time in this paper, may be the most useful structural feature for a rapid tentative identification of ISAV in thin sections.

Acknowledgements. The authors gratefully acknowledge the skilful technical assistance of Turid Kaino. We also thank the local veterinary officers Halvor Hektoen and Marit Nilsen for assistance with sampling at the fish farms.

\section{LITERATURE CITED}

Bächi T, Gerhard W, Lindemann J, Mühlethaler K (1969) Morphogenesis of influenza A virus in Ehrlich ascites tumor cells as revealed by thin-sectioning and freeze-etching. J Virol 4:769-776

Compans RW, Choppin PW (1973) Orthomyxoviruses and paramyxoviruses. In: Dalton AJ, Haguenau F (eds) Ultrastructure of animal viruses and bacteriophages: an atlas. Academic Press, New York, p 213-237

Compans RW, Dimmock NJ (1969) An electron microscopic study of single-cycle infection of chick embryo fibroblasts by influenza virus. Virology 39:499-515

Dannevig BH, Falk K, Namork E (1995) Isolation of the causal virus of infectious salmon anaemia (ISA) in a long-term cell line from Atlantic salmon head kidney. J Gen Virol $76: 1353-1359$

Ghadially FN (1988) Ultrastructural pathology of the cell and matrix, 3rd edn. Butterworths, London, p 602-607 
Hovland T, Nylund A, Watanabe K, Endresen C (1994) Observation of infectious salmon anaemia virus in Atlantic salmon, Salmo salar L. J Fish Dis 17:291-296

McDowell EM, Trumph BF (1976) Histologic fixatives suitable for diagnostic light and electron microscopy. Arch Pathol Lab Med 100:405-414

Morgan C, Rose HM (1968) Structure and development of viruses as observed in the electron microscope VIII. Entry of Influenza virus. J Virol 2:925-936

Murphy BR, Webster RG (1990) Orthomyxoviruses. In: Fields BN, Knipe DM, Chanock RM, Hirsch MS, Melnick JL, Monath TP, Roizman B (eds) Virology, 2nd edn. Raven Press, New York, p 1091-1152

Murphy FA, Harrison AK, Whitfield SG (1973) Bynyaviridae: morphologic and morphogenetic similarities of Bunyamwera serologic supergroup viruses and several other arthropod-borne viruses. Intervirology 1:297-316

Nermut MV (1972) Further investigation on the fine structure of the influenza virus. J Gen Virol 17:317-331

Nylund A, Alexandersen S, Rolland JB, Jakobsen P (1995a) Infectious salmon anemia virus (ISAV) in brown trout. J Aquat Anim Health 7:236-240

Nylund A, Hovland T, Watanabe K, Endresen C (1995b) Presence of infectious salmon anaemia virus (ISAV) in tissues of Atlantic salmon, Salmo salar L., collected during three separate outbreaks of the disease. J Fish Dis 18:135-145

Nylund A, Jakobsen P (1995) Sea trout as a carrier of infectious salmon anaemia virus. J Fish Biol 47:174-176

Responsible Subject Editor: J.-A. Leong, Corvallis, Oregon, USA
Nylund A, Kvenseth AM, Krossøy B (1995c) Susceptibility of wild salmon (Salmo salar L.) to infectious salmon anaemia (ISA). Bull Eur Assoc Fish Pathol 15:152-156

Oxford JS, Schild GC (1990) The Orthomyxoviridae and influenza. In: Collier LH, Timbury MC (eds) Topley \& Wilson's principles of bacteriology, Vol 4, Virology and immunity. Edward Arnold, London, p 292-322

Patterson S, Gross J, Oxford JS (1988) The intracellular distribution of influenza virus matrix protein and nucleoprotein in infected cells and their relationship to haemagglutinin in the plasma membrane. J Gen Virol 69 : $1859-1872$

Reynolds ES (1963) The use of lead citrate at high $\mathrm{pH}$ as an electron-opaque stain in electron microscopy. J Cell Biol $17: 208-212$

Schulze IT (1972) The structure of influenza virus II. A model based on the morphology and composition of subviral particles. Virology 47:181-196

Sommer AI, Mennen S (1996) Propagation of infectious salmon anaemia virus in Atlantic salmon, Salmo salar L. head kidney macrophages. J Fish Dis 19:179-183

Thorud KE (1991) Infectious salmon anaemia. Transmission trials, haematological, clinical chemical and morphological investigations. Dr thesis, Norwegian College of Veterinary Medicine, Oslo

Thorud K, Djupvik HO (1988) Infectious anaemia in Atlantic salmon (Salmo salar L.). Bull Eur Assoc Fish Pathol 8: $109-111$

Manuscript first received: October 2, 1996

Revised version accepted: December 13, 1996 